\title{
CACOAL - RO: A CONSTITUIÇÃO DE UM CAMPESINATO NA FRONTEIRA AGRÍCOLA DA AMAZÔNIA MERIDIONAL
}

\author{
JACOB BINSZTOK \\ Universidade Federal Fluminense
}

\section{Apresentação}

O trabalho investiga o processo de consolidação da fronteira agrícola na Amazônia Meridional, representada pelo município de Cacoal, localizado à margem da rodovia 364, distante cerca de $470 \mathrm{~km}$ de Porto Velho e inserido no denominado Centro-Leste de Rondônia. Trata-se da $3^{\mathrm{a}}$ cidade mais populosa do Estado, pois o Censo de 2.000 revelou um efetivo de 73.525 habitantes, com 51.359 (70\%) concentrando-se na área urbana e 22.167 (30\%) distribuídos pela zona rural, seguindo os discutíveis padrões da urbanização acelerada, que caracteriza grande parte das cidades brasileiras.

Com relação aos espaços ocupados pela produção agropecuária em Cacoal, destacamos a presença de uma forte concentração de pequenos produtores, que na década de 70, provenientes em grande parte do Norte do Espírito Santo, dedicaram-se ao cultivo do café da variedade robusta (conilon) e a uma significativa policultura camponesa, responsável pela produção de ampla variedade de produtos consumidos na

\footnotetext{
* Professor Titular de Geografia Humana do Departamento e do Programa de Pós Graduação em Geografia da Universidade Federal Fluminense. O presente trabalho foi realizado em nov/2001, promovido pelo referido programa. E-mail: rodrigocaetanogeouff@hotmail.com
} 
cidade. O cacau nativo da região é cultivado por um razoável número de produtores, ressaltando-se, ainda, o aumento dos espaços ocupados pela pecuária de corte e leiteira, que utiliza modernas técnicas de produção, como a inseminação artificial e as pastagens plantadas.

Com respeito às relações de trabalho, a pesquisa mostrou a existência de um grande número de meeiros oriundos de vários pontos do país, ocupados principalmente com o cultivo do café e, também, com a pecuária de corte e de leite. Os meeiros, trabalhando ao lado dos pequenos proprietários, constituíram-se em um dos importantes atores para consolidação da fronteira agrícola do Centro-Leste de Rondônia e, conseqüentemente, da Amazônia Meridional.

Uma das iniciativas mais interessantes da municipalidade, para consolidar a fronteira agrícola, ocorreu nos anos 90 , pela reestruturação do ensino de $5^{\mathrm{a}}$ à $8^{\mathrm{a}}$ série nas áreas rurais, implantando-se o Projeto Pró-Campo. Atento às reivindicações dos produtores e com o objetivo de evitar a saída de jovens para estudar na cidade, o projeto, utilizando uma metodologia fundamentada em atividades presenciais e de acompanhamento, procurou conciliar o trabalho destes jovens com os pais na lavoura, típico da organização camponesa, com as tarefas pertinentes ao ensino, mantidas pela Secretaria Municipal de Educação e de Cultura de Cacoal.

\section{Cacoal no processo de ocupação e povoamento de rondônia}

O processo de ocupação e povoamento de Cacoal obedeceu aos ciclos que atingiram Rondônia e que podem ser resumidos da seguinte forma:

$1^{\circ}$ - A partir do século XVII, no período colonial, pela penetração de bandeiras dirigida pelos portugueses. O objetivo principal destes movimentos era a exploração de ouro e outros minerais nos rios Guaporé e Mamoré;

$2^{\circ}$ - No século XVIII, Rondônia apresentou um processo de ocupação caracterizado pela busca do ouro, originando os núcleos populacionais de Pouso Alegre e Casa Redonda;

$3^{\circ}$ - No fim do século XIX, a região atravessou o primeiro ciclo da borracha com migrantes nordestinos ocupando as bacias hidrográficas e avançando em terras bolivianas, gerando um conflito territorial, solucionado pelo Tratado de Petrópolis, assinado em 1903, ficando para o Brasil as terras que deram origem ao Estado do Acre;

$4^{\circ}$ - No início do século XX, a construção da Estrada de Ferro Madeira-Mamoré, no período de 1904 a 1912, favoreceu a imigração de trabalhadores europeus, centro-americanos e nordestinos. A construção da estrada de ferro originou os núcleos urbanos de Porto Velho, Jaci-Paraná, Mutum-Paraná, Abunã e Guajará Mirim.

$5^{\circ}$ - No século passado, entre 1920/40, a Comissão Rondon, responsável pela implantação da linha telegráfica Cuiabá-Porto Velho, instalou 
postos em Vilhena, Marco Rondon, Pimenta Bueno, Ji-Paraná, Ariquemes e Porto Velho. A Comissão Rondon pode ser considerada o embrião do município de Cacoal, ao permitir que um dos seus integrantes, o Sr. Anésio Sena de Carvalho, proveniente da Paraíba, solicitasse terras para a implantação de um seringal às margens do igarapé Pirarara. Em virtude da grande quantidade de seringueiras e de cacau nativo encontrado na área, o integrante da Comissão Rondon designou o empreendimento de Seringal Cacoal, que após o declínio da borracha passou a ser denominado de Fazenda Cacoal.

$6^{\circ}$ - No período de 1941/1945, durante a $2^{\text {a }}$ Guerra Mundial, o Governo Vargas criou o SEMTA (Serviço Especial de Mobilização de Trabalhadores para a Amazônia), dirigido pelo Eng. Paulo de Assis Ribeiro, com a participação do então padre Helder Câmara na coordenação dos trabalhos de orientação religiosa dos "soldados" da borracha. Na época, foram recrutados cerca de 50.000 trabalhadores nordestinos, com o objetivo de reativar a produção dos seringais na Amazônia e em grande parte das bacias hidrográficas de Rondônia. Financiada pela agência governamental norte-americana Rabber Development Corporation, o SEMTA, jamais cumpriu a meta de produzir sessenta mil toneladas do produto por ano, desta forma, os soldados da borracha foram abandonados à própria sorte.

$7^{\circ}$ - Na década de 60 , a extração de cassiterita (estanho), dirigida pelo conglomerado canadense Brascan, atraiu um grande número de garimpeiros para Ariquenes e Porto Velho. Nesta década, também ocorreu a abertura da BR 364, ligando Porto Velho a Cuiabá. Na década de 70, a colonização oficial do INCRA transformou os antigos postos telegráficos de Vilhena, Pimenta Bueno, Ji-paraná e Ariquemes, em núcleos de recepção do movimento migratório mais expressivo do Estado de Rondônia.

\section{Cacoal e o (Re)Ordenamento Territorial de Rondônia}

Pesquisando as origens das cidades de Rondônia, Silva Filho (1995), relata os primórdios da cidade de Cacoal, mostrando que, em 1972, à margem da antiga BR 29 (364), perto do barracão de uma antiga fazenda, acamparam um razoável número de pioneiros provenientes de vários pontos do país e ficaram aguardando a demarcação e distribuição pelo INCRA de lotes do Projeto Integrado de Colonização JiParaná, com uma área prevista de 486.137 ha. destinada ao assentamento de 5.000 famílias. O autor destaca a presença no acampamento dos seguintes pioneiros: Amandio Rodrigues D'Ávila, Olívio de Tal, Siriaco do Nascimento, Manoel Gomes dos Santos, Pedro Alves Corrêa, Jesuíno Rodrigues d'Ávila, Colares Pinto Rabelo, Antônio Petroni, Antenor Nunes de Oliveira (Orlando), e Francisco Nominato Fritz. 
O trabalho de Kemper (2002), mostra que grande parte dos seringalistas e pioneiros, por não possuírem título definitivo de propriedade, tiveram boa parte de suas terras invadidas ou desapropriadas pelo INCRA durante o Regime Militar, não sendo raro terminarem seus dias em dificuldades financeiras e dependendo de familiares para prover suas necessidades, como demonstram as entrevistas realizadas pela autora com amigos e familiares de pioneiros: Anísio Serrão, Manoel do Carmo, João Faustino da Silva, Luiz Caetano de Azevedo, Leônidas Leonel de Oliveira e Clodoaldo Nunes de Almeida, responsável pela introdução do café em Rondônia. Assim, tais atores não se transformaram em oligarcas rurais, pois não conseguiram monetizar a renda da terra, diferente do ocorrido em outras áreas do país.

A publicidade oficial sobre a distribuição de lotes atraiu um notável fluxo de migrantes para as imediações do Projeto, fazendo com que o INCRA também atuasse na distribuição de lotes urbanos, ao construir uma vila no cruzamento da linha 07 com a BR 364, lançando os marcos urbanos de Cacoal. A expansão da Vila e o aumento do tráfego pela rodovia motivaram alguns pioneiros para iniciativas inovadoras, como a construção de pequenos estabelecimentos comerciais destinados ao atendimento do fluxo rodoviário: restaurantes, postos de gasolina, oficinas de reparos de veículos, hotéis, etc.

A importância destes núcleos foi assinalada pelo prof. Orlando Valverde, em estudos realizados na década de 60 , ao longo da rodovia Belém-Brasília (antiga BR 14). Seguindo a tradição da escola geográfica alemã, Valverde chamou estes núcleos de "strassendorf", destacando as especificidades de seu incipiente traçado urbano, que evoluía na forma de um tabuleiro de xadrez e as funções desempenhadas pelos estabelecimentos comerciais pioneiros. Esta é a gênese de um bom número dos atuais núcleos urbanos formados ao longo da BR. 364 e, particularmente, de Cacoal.

Os procedimentos do INCRA, em consonância com o ordenamento proposto pelo regime militar, rapidamente elevaram Cacoal à categoria de município. Assim, o município foi criado pela lei n 6.448 , de 11 de outubro de 1977 , com limites definidos pelo Decreto $\mathrm{n}^{\circ} 81.272$, de 30 de janeiro de 1978 , sendo instalado em $1^{\circ}$ de março de 1982, exatamente dez anos após a chegada dos pioneiros à Fazenda Cacoal. Os limites do município foram assim estabelecidos: ao norte com o Estado de Mato Grosso; ao oeste com o município de Ministro Andreazza; ao sul com o município de Rolim de Moura; a leste/sudeste com o município de Pimenta Bueno e a leste/norte com o município de Espigão D’Oeste (mapa 1).

Analisando o processo de colonização implantado pelo INCRA nos anos 70, na Amazônia Meridional, Oliveira (1990) e Becker (1991) destacaram a importância de dois instrumentos utilizados pelo regime militar para viabilizar a ocupação dos "vazios demográficos" de Rondônia, ressaltando:

a) A consolidação da BR 364, realizada no final dos anos 70 e início dos 80 , principalmente no trecho Cuiabá/Vilhena/Porto Velho, que contou com recursos do Polonoroeste e financiamento do Banco Mundial para ordenar o fluxo de camponeses expropriados pela modernização agrícola no sul/sudeste do país; 


\section{Mapa 1- Localização do Município de Cacoal}

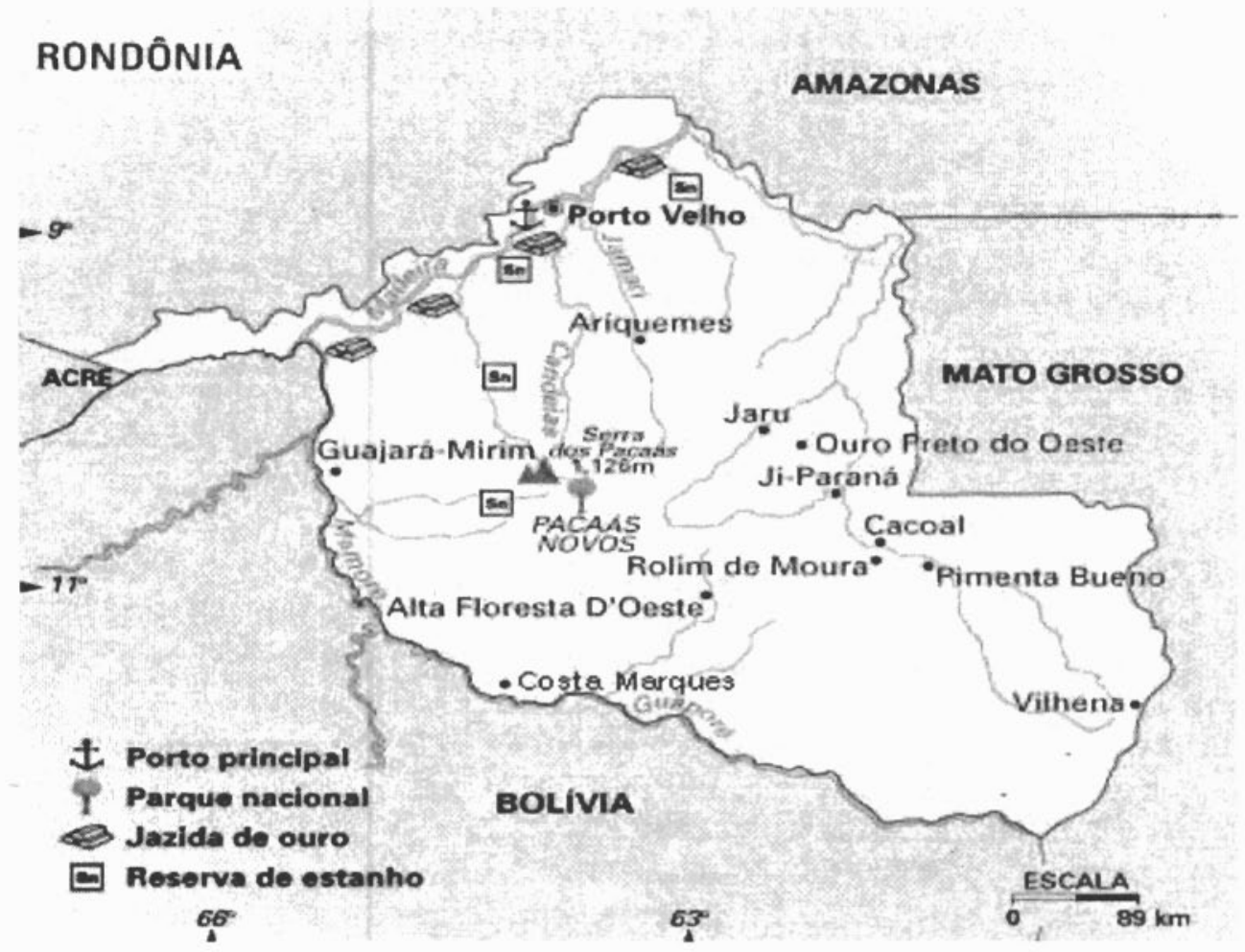

Fonte: Prefeitura Municipal de Cacoal

b) Os Projetos Integrados de Colonização (PIC), concebidos pelo Programa de Integração Nacional (PIN), que ocuparam uma faixa de $100 \mathrm{~km}$ de cada lado da BR. 364, repartida em lotes de aproximadamente 100 ha. distribuídos pelo INCRA aos pioneiros para atenuar os inúmeros focos de tensão no campo brasileiro. Nestas iniciativas

"o INCRA assume a responsabilidade da organização territorial da implantaçāo da infraestrutura física e da administração do Projeto. Realiza o assentamento e a titulação dos beneficiários (parceiros), bem como promove, geralmente de forma indireta, a assistência técnica, o ensino, a saúde e previdência social, a habitação rural, o armazenamento e a comercialização da produção." (INCRA, 1983: VIII / IX) 


\title{
Quadro 1
}

\section{Projetos Integrados de Colonização no Estado de Rondônia}

\author{
Projetos \\ Área (ha.) \\ $\mathrm{N}^{\circ}$ de famílias \\ Área de influência \\ Ouro Preto \\ 512.585 \\ 5.000 \\ Ouro Preto D’Oeste e Ji-Paraná \\ Ji-Paraná \\ 486.137 \\ 5.000
}

Cacoal, Pres. Médici, Rolim de Moura, Pimenta Bueno e Espigão D’’Oeste

Adolfo Rohl

407.210

3.500

Jarú

Paulo de Assis Ribeiro

293.580

3.500

Colorado D'Oeste

Sidney Girão

60.000

600

Guajará-Mirim

Fonte: INCRA-1980

Oliveira (1990); Becker (1991)

Reorganização: Jacob Binsztok/2002 
A leitura das informações contidas no quadro 1, mostra Ouro Preto e Ji-Paraná como os maiores projetos de colonização do Estado de Rondônia, no entanto, apesar de relativamente próximos, em função da sua localização estratégica, Ji-Paraná se destaca pela formação de um bom número de municípios. Logo, os projetos de colonização foram fundamentais para a constituição dos novos municípios, embora com reduzidas estruturas de serviços, mobilizaram lideranças para exercer o poder local e substituir as funções exercidas pelo INCRA.

Nesta perspectiva, podemos afirmar que tanto a BR. 364, quanto os Projetos de Colonização Integrada, cumpriram as finalidades geopolíticas estipuladas pelo regime militar, criando novas esferas de poder local e contribuindo decisivamente para a construção de uma nova ordem territorial no Estado de Rondônia e na Amazônia Meridional.

\section{Campesinato e Consolidação da Fronteira Agrícola}

Com o objetivo de investigar o processo de consolidação da fronteira agrícola no Estado de Rondônia, realizamos pesquisas de campo no município de Cacoal, em nov/2001, procurando conhecer a participação dos diferentes atores sociais no referido processo. Entrevistamos pequenos proprietários, meeiros, comerciantes, feirantes, professores, estudantes, técnicos de instituições públicas, enfim, todos aqueles que pudessem nos ajudar a melhor compreender a construção deste novo ordenamento territorial na Amazônia Meridional.

Ao percorremos as linhas de produção, onde se concentra a atividade agropecuária de Cacoal, nos deparamos com uma segunda leva de migrantes provenientes, em grande parte, do norte do Espírito Santo, de cidades como São Gabriel da Palha, Linhares, Colatina, Mantena, Vila Pavão, e Nova Venécia. Estes produtores adquiriram terras na década de 70/80, organizados em uma estrutura tipicamente camponesa e se dedicaram ao cultivo de café, da variedade "conilon" , caracterizada por maior porte vegetativo e tolerância a temperaturas elevadas.

Diferente da variedade "arábica", o café do tipo "conilon" não é apropriado ao consumo direto, sendo utilizado para fabricação de tintas, para a industria de café solúvel e na composição de "blends" de café torrado, porque auxilia na cor e na consistência da bebida.

A importância de Cacoal na economia cafeeira de Rondônia, pode ser demonstrada pela leitura dos dados contidos no quadro 2 .

Analisando as informações do quadro 2, apesar de verificarmos a cafeicultura de Rondônia distribuída por um razoável número de municípios, Cacoal destaca-se pela liderança da produção em área ocupada e na produtividade. Com relação à produtividade, é importante ressaltar que Cacoal acompanha a média nacional (14.0), significativa para Rondônia, porém baixa se compararmos com os resultados obtidos por Minas Gerais (25.0) e São Paulo (23.0). 


\section{Quadro 2}

Municípios maiores produtores de café - Rondônia - 2001

Municípios

Área (ha)

Produção (saca)

Produtividade(há)

Cacoal

22.037

308.520

14.0

São Miguel de Guaporé

16.620

177.060

10.5

Alto Paraíso

10.700

128.400

12.0

Machadinho do Oeste

9.903

52.420

6.0

Ministro Andreazza

9.121

127.690

14.0

Nova Brasilândia do Oeste

8.904

106.850

12.0

Alta Floresta do Oeste

8.433

118.060

14.0

Novo Horizonte do Oeste

7.853

109.940

14.0 


\begin{tabular}{|lc|}
\hline Rolim de Moura & 7.597 \\
& 100.280 \\
& 13.0 \\
Jaru & 7.361 \\
& 95.690 \\
& 13.0 \\
Sub - total & 108.529 \\
& 1.331 .910 \\
& 12.0 \\
Outros municípios & 104.590 \\
& 1.060 .470 \\
& 10.0 \\
Total & 203.128 \\
& 2.392 .380 \\
& 11.0 \\
\hline
\end{tabular}

Fonte: Levantamento Sistemático da Produção Agrícola (LSPA), IBGE - 2001.

Organizador: Agenor Luiz Delazari

Reorganizador: Jacob Binsztok

As abordagens comparativas são relevantes, mas não devem servir como desestímulo para a cafeicultura de Cacoal, pois os cultivares de São Paulo e Minas Gerais são da variedade "arábica", adaptada às condições morfológicas, climáticas e padrões tecnológicos diferentes de Rondônia.

Na pesquisa de campo, entrevistamos o Sr. Otávio Pavan, que nos informou ter vendido terras em São Gabriel da Palha e adquirido 17 alqueires (paulista) na linha 9 da área rural de Cacoal. Com a propriedade bem cuidada, conservando mata secundária e reflorestando com bandara (condimento natural da culinária oriental), que pode ser cortada no $8^{\circ}$ ano de plantio, o produtor cultiva café "conilon" no espaçamento $3 \times 4$ ou $5 \times 3$, contando com o trabalho de apenas um meeiro, proveniente de Minas Gerais. Demonstrando familiaridade com o mercado, afirmou que não vai deixar de cultivar o produto, mesmo com os seus baixos preços, lembrando que na juventude ajudou na erradicação e posterior plantio de cafezais no Espírito Santo. Para atenuar os efeitos da crise, o referido produtor, vai plantar uma variedade de "conilon" denominada "Paraty", tentando, desta maneira, obter melhores condições de comercialização do produto.

Notamos, na propriedade do Sr.Otávio, o aproveitamento da cobertura verde, ondé ainda encontramos vestígios da derrubada da mata original. A quantidade de fertili- 
dade natural existente é grande, o que explicaria, em parte, a reduzida utilização da análise do solo e da adubação química nos cafezais do município (25\%). A permanência deste quadro não isenta a cafeicultura de Cacoal de futuros problemas decorrentes da redução da fertilidade natural e conseqüente declínio da produção, reproduzindo um ciclo de rendimentos decrescentes na agricultura da Amazônia, como o ocorrido na década de 20 com o algodão na Região Bragantina no Pará.

O escoamento da produção cafeeira de Cacoal é feito pela BR 364 em direção aos portos de Vitória e Paranaguá. O produto é majoritariamente dirigido por tradicionais empresas capixabas como Trevizan e a Cerealista Capixaba e, secundariamente, por paranaenses como Kiko e Máquinas Paraná. Para os técnicos da CEPLAC (Comissão Executiva e de Planejamento da Lavoura Cacaueira), Rondônia ainda não possui uma estrutura de exportação, ficando dependente dos interesses comerciais de outros estados.

Segundo informações obtidas com técnicos, o café de Cacoal é colhido sem estar plenamente maduro, acarretando em uma perda de $40 \%$. O melhoramento da qualidade pode ser obtido mediante o aumento do número de horas nos secadores, cerca de 36 horas, em lugar das 12-14 horas atualmente utilizadas para a maturação do produto.

A policultura típica da produção camponesa é facilmente constatada em grande parte das propriedades rurais de Cacoal. Neste sentido, encontramos a horticultura com a produção de alface, agrião, repolho, abobrinha, brócolis, tomate e cenoura. Também encontramos a fruticultura produzindo manga, côco, araçá, abacaxi, melancia, banana da terra, banana - prata, melão, laranja, fruta de conde, acerola, pokan, pupunha, jaca e cupuaçu. Cultivam cereais como feijão, arroz e milho e ainda cuidam de galinhas caipiras, perus e porcos.

Segundo informações da EMATER, esta policultura é responsável pelo abastecimento de supermercados (Lusitana e Irmãos Gonçalves) e de pelo menos quatro feiras semanais realizadas na cidade. Visitamos a feira realizada no centro da cidade, que não possui características especificas, apresentando certa similitude com as congêneres da área periférica da Região Metropolitana do Rio de Janeiro. Os feirantes nos informaram que pagam mensalmente um aluguel simbólico de $\mathrm{R} \$ 1,00$, com isso, adquirem a licença de instalação da barraca, visando a comercialização de seus produtos.

Com o objetivo de compreender a importância das linhas de produção para o abastecimento da cidade, executando a função do "cinturão verde" de produtos perecíveis, preconizada por Von Thünen, elaboramos o seguinte quadro:

As informações do quadro 3 mostraram as linhas 08,10 e 208 concentrando a produção de hortifrutigranjeiros para o abastecimento de Cacoal. No caso, confirmamos as observações de Coy (1995), mostrando que o acelerado crescimento urbano das cidades pioneiras tem contribuído para a diversificação dos circuitos econômicos e melhorado a renda de determinados produtores rurais. Nas entrevistas, verificamos que uma significativa parcela de feirantes é constituída de produtores ru- 


\section{Quadro 3}

\section{Produtos Comercializados na Feira de Cacoal 2001 \\ Produtos \\ Procedência}

Espinafre, hortelã, mandioca e repolho

Linha 06

Alface, almeirão, abóbora, berinjela, cebolinha, coentro, cenoura, frango, jiló, maxixe, pepino, quiabo, rúcula, pimenta doce, pimenta de cheiro e tomate Linha 08

Abacaxi, abóbora, banana da terra, melão nativo, limão e vagem Linha 208

Feijão verde, jiló, pepino, galinha (engradado), ovos, amendoim, feijão, repolho e farinha

Linha 10

Carne de porco

Linhas 05, 09, 10, Espigão D’Oeste, Alvorada e Rolim de Moura

Feijão, arroz, mandioca, farinha e banana maçã

Linha 13

Galinha (engradada)

Linha 11, Alto Alegre e Pimenta Bueno

Manga, abacaxi

Linha União

Alho

Goiânia.

Condimentos

São Paulo e Rondônia

Cenoura, cebola, beterraba

Paraná

Confecções

Goiânia, São Paulo, Mato Grosso 
rais, que reclamam das dificuldades de transporte, principalmente nos fins de semana, pois, muitas vezes, pernoitam na cidade em condições adversas, evitando os deslocamentos onerosos entre o sítio e a feira.

$\mathrm{Na}$ linha 21, encontramos um dos atores marcantes da heterogeneidade que envolve a fronteira agrícola de Rondônia. Nesta área, visitamos uma comunidade de produtores capixabas descendentes de pomeranos, provenientes de São Gabriel da Palha, Vila Pavão, Afonso Cláudio e Barra do São Francisco. Ainda falam o baixo alemão em casa, entretanto, do ponto de vista religioso, a comunidade apresenta-se dividida entre adeptos da Igreja Católica, Evangélica e Luterana.

Os capixabas da linha 21 possuem uma similitude com os produtores de descendência italiana no cultivo do café. Também se dedicam à produção de leite em propriedades situadas na faixa de 5 a 10 alqueires. A média de produção de leite é de 30 litros diários, comercializados com maquinistas locais e com o laticínio Vale D'Oeste (Espigão D’Oeste), laticínio Nova Esperança (Espigão D'Oeste) e o laticínio Tradição (Cacoal).

Os produtores de origem pomerana adquiram lotes da Companhia Itaporanga, no entanto, os paranaenses, originários em grande parte de Vera Cruz, Cruzeiro do Oeste, Céu Azul e Toledo, chegaram como meeiros, só comprando terras após um período de permanência em Cacoal.

Nas entrevistas, fomos informados que alguns produtores estão vendendo suas propriedades e comprando terras de menor valor em locais distantes como: Conífia (Mato Grosso); Buritis (Rondônia); e São Francisco (Rondônia), aproveitando-se de estradas vicinais pioneiras existentes no município. Outros produtores não venderam as suas propriedades, porém adquiriram novas terras nos locais mencionados.

A contribuição do geógrafo Jean Roche em sua obra: A Colonização Alemã no Espírito Santo, na década de 60, ajudou a compreender o processo de aquisição de terras na fronteira agrícola do estado. O autor denominou de "fazedores de solo", o seguimento do campesinato envolvido na aquisição de terras na fronteira agrícola do norte capixaba. Destarte, tais práticas já eram organizadas nos locais de origem dos migrantes, geralmente destinadas ao assentamento de descendentes de sexo masculino, no caso da colonização pomerana, não devendo ser considerada, portanto, como uma especificidade da disponibilidade de terra na fronteira agrícola de Rondônia.

Alguns seguimentos urbanos, representados por comerciantes, profissionais liberais e funcionários públicos fiéis às raízes patrimonialistas do país, também estão adquirindo pequenos lotes na zona rural ( 1 a 5 alqueires), transformando-os em sítios de fins de semana, estimulando, desta forma, a existência de um razoável mercado de terras em Cacoal.

A presença desses movimentos mostra a importância dos estudos realizados por Velho (1973), sobre a grande mobilidade espacial do campesinato, Oliveira (1991), referente à desterritorialização do campesinato e Coy (1995), advertindo para o gradual fechamento da fronteira agrícola sem sustentabilidade ambiental. Em linhas 
gerais, estes pesquisadores destacaram a incapacidade da fronteira agrícola na solução da geração do trabalho e renda, como, também, admitindo que o campesinato está longe de esgotar sua contribuição para construção de uma nova ordem territorialambiental no país.

\section{Relações de Trabalho no Espaço Agrário de Cacoal}

Analisando as especificidades da colonização do INCRA implantada em Rondônia, Oliveira (1990), demonstra a importância dos meeiros , destacando a seguinte contribuição de Carlos Minc (1985):

A maior parte dos migrantes que chegaram a Rondônia não conseguiu lotes nem no primeiro, nem no segundo ano. Outros ganharam lotes em áreas sem qualquer tipo de acesso, distantes mais de $100 \mathrm{~km}$ das estradas. Tanto num caso como no outro, estes camponeses se instalaram nos lotes já produtivos de parentes ou amigos na qualidade de agregados ou meeiros.

Estas relações de agregados e meeiros são muito importantes, porque são a base do trabalho e das diferenças que se estabeleceram. O meeiro se instala com toda sua família no lote de um colono, enquanto aguarda receber o lote, ou que o lote recebido se tome acessível. Neste período (que pode ser longo) trabalha seu roçado com a família e ainda ajudă ao colono proprietário do lote na implantação da cultura de café ou cacau. Esta relação não deixa de ser um tipo de exploração, mas é a única forma desta família recém chegada sobreviver, e fazer alguma economia para investir mais tarde no seu próprio lote. Geralmente as famílias, quando deixam seus locais de origem, já têm o endereço de algum conhecido com o lote, que se dispõe a receber novos colonos como meeiros. Esta relação constitui assim a porta de entrada dos novos migrantes (MINC, apud OLIVEIRA, 1990: p.44/45).

A presença de meeiros trabalhando ao lado de pequenos proprietários é uma constante no espaço agrário de Cacoal. Segundo informações da EMATER, cerca de $60 \%$ dos acertos realizados entre meeiros e proprietários são verbais e por vezes conflituosos, não se pautando nos Contratos de Parceria Agrícola previstos no art. 92 do Estatuto da Terra, Lei 4.504 de 30/11/1964. O instrumento legal estipula que, $50 \%$ das produções de café ou de cacau, sejam divididos com o proprietário e que toda "lavoura branca" consista em propriedade do meeiro, como a de mandioca, milho, feijão e frutas.

Alguns produtores adotam o Contrato de Parceria Agrícola como garantia contra futuras reivindicações judiciais. Atualmente os proprietários possuem de um a dois meeiros. Em outras ocasiões, propriedades de 42 alqueires chegaram a contar com o trabalho de três meeiros.

Na pecuária, registramos a presença de dois tipos de meeiros: o primeiro representado pelo meeiro sem terra, remunerado pelo peso adicional da engorda sob a sua responsabilidade; o segundo caracterizado pelo meeiro com terra, que recebe o novi- 
lho do fazendeiro e reparte igualmente o lucro. Em ambos a produção do leite pertence ao meeiro.

As linhas de crédito para os meeiros são concedidas pelo Fundo de Amparo ao Trabalhador (FAT), e as dos pequenos produtores pelo Programa Nacional de Agricultura Familiar (PRONAF) e pelo Rural-Rápido, situados na faixa de R $\$ 1.000 .00$ a $\mathrm{R} \$ 5.000 .00$ reais, operados respectivamente pelo Banco do Brasil e Banco da Amazônia Sociedade Anônima (BASA). No momento, os pequenos produtores só perdem suas terras por dívidas no banco, se as tiverem ofertado como garantias hipotecárias. Este procedimento confirma os estudos de Oliveira (1990), mostrando que a atual fase do desenvolvimento capitalista não está interessada em expropriar terras e sim apropriar-se da renda da terra por intermédio da exploração do trabalho dos pequenos proprietários.

Proprietários e meeiros utilizam o trabalho temporário, em abril, maio, junho e julho, na safra do café, recrutando diaristas para coleta do produto. Assim, são mobilizados trabalhadores do município limítrofe de Espigão D’Oeste, empregadas domésticas, menores, enfim, uma verdadeira corrida para a safra de café em Cacoal, remunerado em $\mathrm{R} \$ 1.50$ o preço do latão no ano de 2001 , atingindo cerca de $\mathrm{R} \$$ 15.00 a diária da mão de obra temporária.

A incorporação do trabalho infantil na cafeicultura de Cacoal, típica da organização camponesa, foi observada em conversa com os alunos da Escola Cruzeiro do Norte, na linha 21. Declararam prazerosamente colaborar nas tarefas familiares, apanhando café, cuidando de irmãos, capinando, desbastando café, enchendo vasilhas, varrendo a casa e fervendo o leite para fazer leite de côco. No caso, não se trata de exploração ou de sobretrabalho infantil, comumente utilizado em outros setores da atividade agrícola, mas da inserção destes jovens na lógica de produção da unidade familiar camponesa.

Os jovens das áreas rurais são atendidos por 19 escolas municipais responsáveis pelo ensino fundamental e pelo Projeto Pró-Campo, inspirado pelo método Paulo Freire, compatibilizando o trabalho agrícola com as atividades escolares. O Projeto ministra o conteúdo curricular de $5^{\mathrm{a}}$ a $8^{\mathrm{a}}$ série, para cerca de 1.000 estudantes, mediante a utilização de um sistema alternativo, envolvendo presença e atividades extraclasse complementares. A etapa presencial é realizada com os docentes, deslocando-se para as unidades escolares e permanecendo à disposição dos alunos durante 8 horas uma vez por semana, com os demais dias destinando-se às atividades complementares extraclasse.

A recente saída de produtores de áreas rurais de Cacoal, parece ter contribuído para uma reestruturação do Pró-campo. Porém não ocorreu o fechamento de escolas como em Ji-Paraná, conforme o relato de Coy (1995). No entanto, foram realizadas fusões de unidades escolares, que não chegaram a interferir na capilaridade do sistema e, conseqüentemente, no acesso às atividades do Projeto, pois a Prefeitura colocou um serviço de ônibus para o transporte dos alunos. 


\section{Considerações Finais}

1 - A ordem territorial, construída no município, não obedeceu a uma lógica empresarial, nem tampouco foi ditada pelos interesses das tradicionais oligarquias rurais. A fronteira neste trecho da BR 364, foi majoritariamente constituída de pequenos comerciantes, camponeses, funcionários públicos, provenientes de vários pontos do país, formando uma comunidade dotada de capacidade inovadora, conforme comprovamos no decorrer do trabalho. Assim, tornamse relevantes iniciativas de instituições públicas e privadas, destinadas à implantação de micro e pequenos empreendimentos, visando ampliar a geração de emprego e renda em Cacoal. Tais iniciativas são urgentes na medida em que observamos o fechamento da fábrica da Coca-Cola, transferida para Manaus, eliminando cerca de 500 postos de trabalho no município.

2 - A pesquisa mostrou que o Estado de Rondônia precisa organizar uma estrutura de escoamento da produção cafeeira para Porto Velho, semelhantemente ao realizado pelo Grupo Maggi com a soja de Matogrosso, evitando, com isto, os onerosos custos de frete para os portos do Sudeste. Caso persista o quadro de dependência, a produção cafeeira rondoniense corre o risco de tornar-se uma expansão da fronteira agrícola do Espírito Santo e do Paraná na Amazônia Meridional. As mudanças neste setor deverão ser negociadas, pois são conhecidas as relações de confiança existentes entre produtores e intermediários capixabas e paranaenses. Em nossa opinião, a municipalidade e o estado deveriam ofertar incentivos à formação de uma rede de intermediários, para inverter o fluxo de comercialização, direcionando-o para Porto Velho, colaborando, deste modo, para que Rondônia atinja uma posição de destaque nas exportações de café do país.

3 - O trabalho demonstrou a necessidade de estimular formas de intercâmbio com entidades ambientalistas nacionais e internacionais, visando a obtenção de um certificado ambiental (selo verde), principalmente para produção de café, que é cultivado com reduzida quantidade de defensivos químicos. Empenhada em diversificar suas atividades, a Comissão Executiva de Planejamento da Lavoura Cacaueira (CEPLAC), pode contribuir para a seleção e orientação de produtores orgânicos do município.

4 - A cidade possui duas instituições dedicadas ao ensino superior: uma de âmbito federal, representada pelo campus da Universidade Federal de Rondônia (UNIR), e outra, na esfera privava, denominada União das Escolas Superiores de Cacoal (UNESC). Cumprindo atividades de rotina, estas instituições não conseguiram formatar propostas de desenvolvimento local-regional; praticamente ignoram o meio rural do município, embora existam recursos disponíveis oferecidos pelas agências governamentais (CNPQ, CAPES, FINEP) para estimular tais projetos. Em função da longa distância entre Cacoal e Porto Velho, o campus da UNIR, à semelhança da Universidade Federal de Goiás, 
poderia desenvolver convênios com a municipalidade, como ocorre nas cidades do interior goiano de Jataí e Catalão, onde as Prefeituras compartilham a administração dos campos avançados com a UFG.

CACOAL - RO: A CONSTITUIÇÃO DE UM CAMPESINATO NA FRONTEIRA AGRÍCOLA DA AMAZÔNIA MERIDIONAL

Resumo: O trabalho investiga a constituição de um campesinato proveniente do Espírito Santo e dedicado à cafeicultura no município de Cacoal - RO. A pesquisa mostra o processo de ocupação e as relações de trabalho, imprescindíveis para a compreensão da ordem territorial e ambiental implantada na fronteira agrícola da Amazônia Meridional. Elaboramos um balanço apontando os avanços e os limites com que se defronta o processo de consolidação deste campesinato, localizado em uma das áreas rurais mais dinâmicas da Amazônia.

Palavras-chave: Campesinato, cafeicultura, fronteira, relações de trabalho e Amazônia.

CACOAL - RO: CONSTITUTION OF A PEASANTRY ON AGRICULTURAL FRONTIER AT SOUTHERN AMAZÔNIA.

Abstract: This work researches a peasantry constitution whose peasants arrived from the State of Espírito Santo to dedicate to coffee plantation at Cacoal - RO. This research shows the occupation process and work relations necessary to understand territory and environmental orders implanted on agricultural frontier at Southern Amazonia. We also made a balance showing advances and limits on this process of peasantry consolidation located at one of more dynamic rural areas at Amazonia.

Key words: Peasantry; coffee plantation; frontier; work relations; Amazonia.

\section{BIBLIOGRAFIA}

BECKER, B.K. 1991. Amazônia. Série Princípios, São Paulo, Editora Ática.

BINSZTOK, J. 2002. Cacoal: Campesinato e Cafeicultura na Fronteira Agrícola do Centro-Leste

de Rondônia. Anais do XVI Encontro Nacional de Geografia Agrária, Campus IIIPetrolina, UFPE.

COY, M. 1995. Cidades Pioneiras e Desenvolvimento Sustentável na Amazônia Brasileira.

Transformação Sócio-Econômica e Desafios para o Planejamento nas Frentes Pioneiras, Geosul n 19/20 - Ano X, Rio Grande do Sul.

INCRA. 1983. Instituto Nacional de Colonização e Reforma Agrária. Colonização em dados, Brasília.

KEMPER, Lourdes. 2002. Cacoal: Sua História Sua Gente. Editora Grafopel. Goiânia, Goiás.

OLIVEIRA, A. U. 1990. Amazônia, Monopólio, Expropriação e Conflito, Campinas, São Paulo, Papirus.

1991. Integrar para Entregar. Políticas Públicas e Amazônia, Campinas, São Paulo, Papirus.

ROCHE, J. 1968. A Colonização Alemã no Espírito Santo, São Paulo, USP. 
SILVA FILHO, GA. 1995. Toponímia de Rondônia, Revista Brasileira de Geografia, V. $57, \mathrm{n}^{\circ} 3$, Rio de Janeiro, IBGE.

VELHO. O. G. 1979. Capitalismo Autoritário e Campesinato. (Um estudo comparativo da fronteira em movimento). São Paulo, DIFEL. 